\title{
Health status of users of hormone replacement therapy by hysterectomy status in Western Australia
}

\section{J Lambert, J A Y Straton, M W Knuiman, H C Bartholomew}

J Epidemiol Community Health 2003;57:294-300

See end of article for authors' affiliations (.....................

Correspondence to: Professor M W Knuiman, School of Population Health, The University of Western Australia, 35 Stirling Highway, Crawley WA 6009, Australia; matthew@dph.uwa.edu.au

Accepted for publication 11 September 2002

\begin{abstract}
Study objectives: To compare the demographic, behavioural, and biological correlates of use of hormone replacement therapy (HRT) in women with an intact uterus and women who have undergone hysterectomy.

Design: Cross sectional analysis of data from the Busselton Health Study and the 1994 Healthway-National Heart Foundation Risk Factor Survey.

Setting: Busselton and Perth, Western Australia, 1994.

Participants: 2540 women aged 35-79 years.

Main outcome measures: Demographic, behavioural, and biological correlates of use of HRT by hysterectomy status.

Results: In women with an intact uterus, after adjustment for age and place of residence, current use of HRT was significantly associated with having a professional level of occupation, ever use of alcohol, having a history of smoking, and a lower body mass index. Current users of HRT had significantly lower levels of total cholesterol and higher levels of triglycerides than non-users. In women who had undergone hysterectomy, the only non-biological characteristic associated with use of HRT was having a history of smoking. Current users of HRT had lower levels of systolic blood pressure, lower levels of LDL cholesterol, higher levels of HDL cholesterol, and higher levels of triglycerides. The association between use of HRT and participation in exercise, level of systolic blood pressure, level of HDL cholesterol, and total/HDL cholesterol ratio varied significantly by hysterectomy status. After adjustment for age and place of residence, the mean levels of systolic and diastolic blood pressure, body mass index, waist/ hip ratio, LDL cholesterol, and total/HDL cholesterol ratio were highest in women who had undergone hysterectomy and were not using HRT.

Conclusions: Demographic/behavioural and biological correlates of use of HRT varied depending on hysterectomy status. Demographic and behavioural characteristics were more important as selection factors for use of HRT in women with an intact uterus than in women who had undergone hysterectomy. Women who had undergone hysterectomy and were not using HRT had a significantly worse profile for CHD than did women with an intact uterus. These results indicate that any bias in estimates of the protective effect of HRT on risk of CHD in observational studies is likely to depend on the prevalence of hysterectomy within the study population. Hysterectomy status needs to be taken into account in any studies that investigate the effect of HRT on risk of CHD.
\end{abstract}

$\mathrm{T}$ here have been numerous studies of the relation between hormone replacement therapy (HRT) and coronary heart disease (CHD). ${ }^{12}$ In observational studies, current users of HRT have consistently been shown to have a better cardiovascular risk factor profile than non-users and to have a lower risk of cardiovascular events. ${ }^{13}$ However, some studies have shown that users of HRT have a better risk factor profile before $\mathrm{HRT}^{45}$ and it has therefore been argued that the protective effect of HRT on risk of CHD has been over-estimated..$^{6-8}$ This argument is reinforced by the failure of two recent randomised trials involving women with established $\mathrm{CHD}^{9}{ }^{10}$ to show a protective effect. ${ }^{11}$ Results of randomised trials in women without CHD are not yet clear. The PEPI study showed improved lipoprotein and lower fibrinogen levels in women using HRT. ${ }^{12}$ On the other hand, in the Women's Health Initiative, the comparison of the effect of combined HRT (oestrogen plus progestin) with placebo in women with an intact uterus showed a slight increase in risk of CHD and other cardiovascular events (stroke and pulmonary embolism) after five years. This arm of the trial was stopped prematurely because of an increased risk of breast cancer and an excess of risks over benefits as measured by a global index. ${ }^{13}$ The unopposed oestrogen component of the trial, involving women who had undergone hysterectomy, is continuing, with results expected in $2005 .^{14}$
An important confounding variable in the study of the relation between HRT and CHD, not adequately accounted for in previous studies, is whether or not a woman has had a hysterectomy. Hysterectomy has consistently been shown to be the primary determinant of use of HRT in women around the world, ${ }^{15-19}$ and there is evidence that women who have undergone hysterectomy differ from women with an intact uterus with respect to important risk factors for $\mathrm{CHD}^{20-22}$ and have a greater risk of CHD. ${ }^{23}{ }^{24}$ Estimates of the effect of HRT on risk of CHD from observational studies are largely based on women who have undergone hysterectomy ${ }^{125}$ and few studies of the correlates of use of HRT have stratified by hysterectomy status.

It should be noted that hysterectomy is likely to be the important confounding variable, not the removal of ovaries. Numerous studies have shown the decline in ovarian function associated with hysterectomy even if the ovaries are not removed. ${ }^{26-28}$ Furthermore, hysterectomy status, rather than ovarian status, is the main determinant of whether women are prescribed oestrogen or oestrogen combined with a

Abbreviations: HRT, hormone replacement therapy; $\mathrm{CHD}$, coronary heart disease 
Table 1 Prevalence of hysterectomy and current use of HRT by age group in Busselton and Perth women in 1994

\begin{tabular}{|c|c|c|c|c|c|c|c|}
\hline \multirow{2}{*}{$\begin{array}{l}\text { Location } \\
\text { of survey }\end{array}$} & \multirow[b]{2}{*}{ Age } & \multirow[b]{2}{*}{$\mathrm{N}$} & \multirow[b]{2}{*}{$\% *$} & \multirow{2}{*}{$\begin{array}{l}\text { Prevalence of } \\
\text { hysterectomy } \\
(\%)\end{array}$} & \multirow{2}{*}{$\begin{array}{l}\text { Prevalence of } \\
\text { current use of } \\
\text { HRT (\%) }\end{array}$} & \multicolumn{2}{|c|}{$\begin{array}{l}\text { Prevalence of current use of HRT } \\
\text { by hysterectomy status }(\%) \dagger\end{array}$} \\
\hline & & & & & & No hysterectomy & Hysterectomy \\
\hline \multirow[t]{5}{*}{ Busselton } & $35-49$ & 741 & 43.6 & 12.0 & 8.9 & 4.1 & 43.8 \\
\hline & $50-59$ & 370 & 21.8 & 31.9 & 42.4 & 34.5 & 59.3 \\
\hline & $60-69$ & 354 & 20.8 & 31.6 & 30.5 & 23.5 & 45.5 \\
\hline & $70-79$ & 234 & 13.8 & 34.0 & 18.3 & 11.1 & 32.4 \\
\hline & All & 1699 & 100.0 & 23.5 & 21.5 & 14.2 & 45.4 \\
\hline \multirow[t]{5}{*}{ Perth } & $35-49$ & 291 & 34.6 & 15.1 & 8.2 & 4.9 & 27.3 \\
\hline & $50-59$ & 286 & 34.0 & 36.0 & 45.8 & 38.2 & 59.2 \\
\hline & $60-69$ & 264 & 31.4 & 37.9 & 27.3 & 18.3 & 42.0 \\
\hline & $70-79$ & - & - & - & - & - & - \\
\hline & All & 841 & 100.0 & 29.4 & 27.0 & 18.9 & 46.6 \\
\hline
\end{tabular}

*Cell values are column percentages for age distribution. †Cell values are column percentages for each category of hysterectomy status.

Table 2 Association (odds ratio and $95 \%$ confidence intervals) between current use of HRT and demographic and behavioural variables by hysterectomy status in Busselton and Perth women combined after adjustment for age group and place of residence

\begin{tabular}{|c|c|c|c|c|c|}
\hline \multirow[b]{2}{*}{ Description of variables } & \multicolumn{2}{|c|}{ No hysterectomy } & \multicolumn{2}{|c|}{ Hysterectomy } & \multirow{2}{*}{$\begin{array}{l}\mathrm{p} \text { Value for } \\
\text { interaction with } \\
\text { hysterectomy } \\
\text { status* }\end{array}$} \\
\hline & OR & $95 \% \mathrm{Cl}$ & OR & $95 \% \mathrm{Cl}$ & \\
\hline \multicolumn{6}{|l|}{ Demographic variables } \\
\hline \multicolumn{6}{|l|}{ Partner } \\
\hline Married/de facto & 1 & & 1 & & \\
\hline Widowed & 1.04 & 0.65 to 1.67 & 0.63 & 0.33 to 1.18 & \\
\hline Separated/divorced & 0.95 & 0.58 to 1.55 & 1.09 & 0.65 to 1.83 & \\
\hline Single & 2.18 & 1.04 to 4.56 & 1.07 & 0.34 to 3.37 & 0.457 \\
\hline \multicolumn{6}{|l|}{ Place of birth } \\
\hline Australia & 1 & & 1 & & \\
\hline United Kingdom & 1.31 & 0.91 to 1.89 & 1.49 & 0.98 to 2.27 & \\
\hline Other & 0.73 & 0.44 to 1.21 & 0.85 & 0.44 to 1.61 & 0.957 \\
\hline \multicolumn{6}{|l|}{ Occupation } \\
\hline $\begin{array}{l}\text { Unemployed/retired/no } \\
\text { occupation reported }\end{array}$ & 1 & & 1 & & \\
\hline Professional/managerial & 1.50 & 1.02 to 2.22 & 1.59 & 0.95 to 2.66 & \\
\hline Skilled labour & 1.53 & 0.51 to 4.58 & 0.79 & 0.21 to 2.93 & \\
\hline Selling/clerical & 1.20 & 0.76 to 1.90 & 1.55 & 0.87 to 2.74 & \\
\hline Labouring/plant operation & 0.98 & 0.66 to 1.45 & 1.28 & 0.82 to 1.99 & 0.256 \\
\hline \multicolumn{6}{|l|}{ Behavioural variables } \\
\hline \multicolumn{6}{|c|}{ Participation in regular physical activity } \\
\hline No & 1 & & 1 & & \\
\hline Yes & 1.34 & 0.97 to 1.86 & 0.83 & 0.57 to 1.21 & 0.049 \\
\hline \multicolumn{6}{|l|}{ Ever drunk alcohol } \\
\hline No & 1 & & 1 & & \\
\hline Yes & 1.91 & 1.23 to 2.97 & 1.68 & 1.02 to 2.79 & 0.949 \\
\hline \multicolumn{6}{|l|}{ Smoking status } \\
\hline Never smoked & 1 & & 1 & & \\
\hline Ex-smoker & 1.67 & 1.24 to 2.26 & 1.62 & 1.12 to 2.35 & \\
\hline $1-14$ cigarettes per day & 1.84 & 0.97 to 3.50 & 1.75 & 0.75 to 4.08 & \\
\hline $15+$ cigarettes per day & 1.65 & 0.91 to 3.01 & 0.98 & 0.53 to 1.79 & 0.744 \\
\hline
\end{tabular}

progestin. ${ }^{29}$ Women with an intact uterus are more likely to use combined therapy (oestrogen plus progestin) to protect against endometrial cancer rather than oestrogen alone. ${ }^{29} 30$ Progestin in the HRT regimen may attenuate the benefit of oestrogen in reducing risk of CHD, and the recently published results of the Women's Health Initiative have in fact shown a small increase in CHD in women using a combined regimen. ${ }^{12}{ }^{13}{ }^{31}$ Thus the impact of different regimens of HRT on risk factors for CHD is another source of potential confounding associated with hysterectomy status.

The availability of data from two population based studies in Western Australia, provides an opportunity, within the limitations of a cross sectional study, to examine the association between a variety of behavioural and biological risk factors for CHD and current use of HRT, stratifying for hysterectomy status.

\section{METHODS}

\section{Busselton sample}

Repeated cross sectional health surveys of all adults and school children were conducted in the shire of Busselton in Western Australia over the period 1966 to $1983 .^{32}$ A follow up survey of all participants in the 1966 to 1983 surveys (including those who had left Busselton) was conducted in 1994/95. 


\begin{tabular}{|c|c|c|c|c|c|}
\hline \multirow{2}{*}{$\begin{array}{l}\text { Description of } \\
\text { biological variables }\end{array}$} & \multicolumn{2}{|c|}{ No hysterectomy } & \multicolumn{2}{|c|}{ Hysterectomy } & \multirow{2}{*}{$\begin{array}{l}\text { p Value for interaction } \\
\text { with hysterectomy } \\
\text { status* }\end{array}$} \\
\hline & OR & $95 \% \mathrm{Cl}$ & OR & $95 \% \mathrm{Cl}$ & \\
\hline \multicolumn{6}{|c|}{ Systolic blood pressure $(\mathrm{mm} \mathrm{Hg})$} \\
\hline$\leqslant 111$ & 1 & & 1 & & \\
\hline $112-123$ & 1.28 & 0.85 to 1.93 & 0.75 & 0.44 to 1.27 & \\
\hline $124-139$ & 1.17 & 0.77 to 1.77 & 0.76 & 0.45 to 1.28 & \\
\hline $139+$ & 0.76 & 0.48 to 1.21 & 0.63 & 0.37 to 1.10 & 0.021 \\
\hline \multicolumn{6}{|c|}{ Diastolic blood pressure $(\mathrm{mm} \mathrm{Hg})$} \\
\hline$\leqslant 69$ & 1 & & 1 & & \\
\hline $70-75$ & 1.04 & 0.70 to 1.56 & 1.26 & 0.76 to 2.08 & \\
\hline $76-82$ & 1.22 & 0.83 to 1.79 & 0.84 & 0.52 to 1.35 & \\
\hline $83+$ & 0.79 & 0.52 to 1.19 & 0.93 & 0.58 to 1.51 & 0.127 \\
\hline \multicolumn{6}{|l|}{ Waist/hip ratio } \\
\hline$\leqslant 0.74$ & 1 & & 1 & & \\
\hline $0.75-0.78$ & 1.00 & 0.69 to 1.46 & 1.04 & 0.63 to 1.72 & \\
\hline $0.79-0.83$ & 0.82 & 0.56 to 1.19 & 0.91 & 0.57 to 1.46 & \\
\hline $0.84+$ & 0.72 & 0.48 to 1.08 & 0.59 & 0.36 to 0.97 & 0.427 \\
\hline \multicolumn{6}{|c|}{ Body mass index $\left(\mathrm{kg} / \mathrm{m}^{2}\right)$} \\
\hline$\leqslant 22.58$ & 1 & & 1 & & \\
\hline $22.59-25.10$ & 0.81 & 0.56 to 1.17 & 0.88 & 0.54 to 1.45 & \\
\hline $25.11-28.56$ & 0.52 & 0.35 to 0.76 & 0.77 & 0.47 to 1.24 & \\
\hline $28.57+$ & 0.49 & 0.33 to 0.72 & 0.61 & 0.38 to 0.98 & 0.818 \\
\hline \multicolumn{6}{|c|}{ Total cholesterol (mmol/l) } \\
\hline$\leqslant 4.95$ & 1 & & 1 & & \\
\hline $4.96-5.64$ & 0.88 & 0.58 to 1.31 & 0.72 & 0.43 to 1.22 & \\
\hline $5.65-6.41$ & 0.75 & 0.50 to 1.13 & 0.83 & 0.49 to 1.38 & \\
\hline $6.42+$ & 0.45 & 0.29 to 0.70 & 0.97 & 0.58 to 1.63 & 0.090 \\
\hline \multicolumn{6}{|c|}{$\mathrm{HDL}$ cholesterol (mmol/l) } \\
\hline$\leqslant 1.25$ & 1 & & 1 & & \\
\hline $1.26-1.50$ & 1.03 & 0.71 to 1.50 & 1.28 & 0.78 to 2.11 & \\
\hline $1.51-1.80$ & 1.02 & 0.69 to 1.50 & 1.69 & 1.05 to 2.73 & \\
\hline $1.81+$ & 1.05 & 0.72 to 1.54 & 4.12 & 2.60 to 6.54 & $<0.001$ \\
\hline \multicolumn{6}{|c|}{ LDL cholesterol (mmol/l) } \\
\hline$\leqslant 2.93$ & 1 & & 1 & & \\
\hline $2.94-3.50$ & 0.81 & 0.54 to 1.21 & 0.89 & 0.54 to 1.47 & \\
\hline $3.51-4.20$ & 0.72 & 0.48 to 1.06 & 0.62 & 0.38 to 1.00 & \\
\hline $4.21+$ & 0.47 & 0.31 to 0.71 & 0.52 & 0.32 to 0.85 & 0.347 \\
\hline \multicolumn{6}{|l|}{ Triglycerides (mmol/l) } \\
\hline$\leqslant 0.70$ & 1 & & 1 & & \\
\hline $0.71-1.00$ & 1.61 & 1.06 to 2.46 & 1.47 & 0.85 to 2.55 & \\
\hline $1.01-1.50$ & 1.56 & 1.01 to 2.41 & 1.50 & 0.87 to 2.58 & \\
\hline $1.51+$ & 1.13 & 0.72 to 1.77 & 1.69 & 1.00 to 2.85 & 0.414 \\
\hline \multicolumn{6}{|c|}{ Total/HDL cholesterol ratio } \\
\hline$\leqslant 3.00$ & 1 & & 1 & & \\
\hline $3.01-3.67$ & 0.89 & 0.60 to 1.30 & 0.72 & 0.44 to 1.16 & \\
\hline $3.68-4.65$ & 0.77 & 0.52 to 1.14 & 0.54 & 0.33 to 0.88 & \\
\hline $4.66+$ & 0.71 & 0.48 to 1.04 & 0.29 & 0.18 to 0.47 & 0.001 \\
\hline
\end{tabular}

${ }^{*} \mathrm{p}$ Value for the likelihood ratio test of the interaction term.

This included a comprehensive self administered health questionnaire, physical examination and tests by trained personnel; blood samples were taken for biochemical and other analyses (http://bsn.uwa.edu.au). The Busselton women eligible for this investigation were the 2310 women attending the 1994/95 survey who were aged 35 to 79 years at that time. Women with incomplete data $(\mathrm{n}=611)$ for any variables under investigation were excluded leaving 1699 women in the final analyses.

\section{Perth sample}

The Perth women were part of the 1994 National Heart Foundation Risk Factor Survey. They were also controls in a case-control study of risk factors for acute myocardial infarction in women aged 35-69. For each five year age group, 152 were selected from the Perth electoral roll and invited to attend a clinic where they completed a self administered questionnaire and underwent a physical examination by a trained nurse. Additional women (17 aged 45-54 and 264 aged 55-64) were randomly selected from the electoral roll for purposes of the case-control study. Of the 1345 women invited to the survey, $75.3 \%(\mathrm{n}=943)$ attended. After exclusion of women with any missing information $(n=102), 841$ women remained in the present analyses. The questionnaire included demographic variables, aspects of lifestyle related to CHD, and medical and gynaecological history. Further information concerning use of HRT was collected in a telephone interview.

\section{Ethical considerations}

The Committee for Human Rights of the University of Western Australia approved the protocol for the two surveys.

\section{Data analysis}

Variables evaluated as correlates of current use of HRT were grouped into demographic (age, marital status, country of birth, and level of occupation), behavioural (leisure time physical activity, ever use of alcohol and smoking) and biological (systolic and diastolic blood pressure, body mass index $\left(\mathrm{kg} / \mathrm{m}^{2}\right)$, waist to hip ratio, total cholesterol $(\mathrm{mmol} / \mathrm{l})$, HDL cholesterol ( $\mathrm{mmol} / \mathrm{l})$, LDL cholesterol $(\mathrm{mmol} / \mathrm{l})$ and triglycerides (mmol/l) and total to HDL cholesterol ratio) categories.

After first confirming the (age specific) similarities for Busselton and Perth subjects, the two groups were combined for 
analyses although place of residence was included in all models. Logistic regression analysis was performed to determine the place of residence and age adjusted odds ratio (and 95\% confidence intervals) of current use of HRT for each demographic, behavioural, and biological variable separately for women with and without a hysterectomy. The odds ratio estimates observed in women with and without hysterectomy were compared by fitting a joint model including both groups and calculating the $\mathrm{p}$ value of the likelihood ratio statistic of the interaction term representing the individual variable and hysterectomy status. The actual interaction $\mathrm{p}$ values are reported and, as a total of 15 variables were assessed, we have only highlighted and interpreted interactions with $\mathrm{p}<0.025$ as statistically significant. Finally, multivariate logistic regression analyses were performed to determine the independent correlates of HRT use separately for women who had undergone hysterectomy and women with an intact uterus. Separate reverse stepwise analyses were first performed for all demographic/behavioural variables and biological variables and the terms retained in each model were then combined and a second reverse stepwise procedure was conducted to obtain the final model. A p value of less than 0.05 was the criterion used to retain variables in the model because the purpose was to compare the list of correlates for the two groups and a more stringent criterion may have discarded relevant variables.

In a separate analysis, the mean level for each biological variable was ascertained by hysterectomy status and current use of HRT, after adjustment for age as a continuous variable (age and age squared) and place of residence. A pairwise comparison of means was then conducted. The mean of each of the three groups, users and non-users of HRT with an intact uterus and users of HRT who had undergone hysterectomy, was compared with the mean of the group of women who had undergone hysterectomy and were not current users of HRT.

\section{RESULTS}

As shown in table 1 there were differences in the age distribution of the two study samples. However, the overall and age specific prevalence of hysterectomy and current use of HRT were similar in the two surveys. Apart from age, the distributions of demographic and behavioural variables were similar in the two study populations, and data from Perth and Busselton were combined in all other analyses with adjustments made for age and place of residence. About 15\% of women aged less than 50 and about one third of women aged 50 or over reported having undergone hysterectomy. The age specific prevalence of current use of HRT varied by hysterectomy status. For example, among women aged $50-59,60 \%$ of women who had undergone hysterectomy were using HRT compared with $35 \%$ of women with an intact uterus.

As shown in table 2, after adjustment for age group and place of residence, current use of HRT in women with an intact uterus was significantly associated with being single, having a professional level of occupation, having ever drunk alcohol and being a ex-smoker. In women who had undergone hysterectomy, only being an ex-smoker and having ever drunk alcohol had a significant association with current use of HRT.

Table 3 shows that association between current use of HRT and systolic blood pressure, level of HDL cholesterol, and total/HDL cholesterol ratio varied significantly by hysterectomy status. In women who had undergone hysterectomy, levels of systolic blood pressure tended to be lower in current users of HRT, while in women with an intact uterus there was no clear association. In both groups, total/HDL cholesterol ratio tended to be lower in current users of HRT but the strength of the association was greater in women who had undergone hysterectomy. Current use of HRT was associated with higher levels of HDL cholesterol in women who had undergone hysterectomy but not in women with an intact uterus.
Table 4 Independent correlates of current use of HRT in women with an intact uterus after adjustment for age group and place of residence

\begin{tabular}{|c|c|c|}
\hline Description of variable & Odds ratio & $95 \% \mathrm{Cl}$ \\
\hline \multicolumn{3}{|l|}{ Age group } \\
\hline $35-39$ & 1 & \\
\hline $40-44$ & 4.64 & 1.29 to 16.67 \\
\hline $45-49$ & 17.97 & 5.29 to 61.04 \\
\hline $50-54$ & 75.40 & 22.63 to 244.6 \\
\hline $55-59$ & 126.20 & 37.98 to 419.4 \\
\hline $60-64$ & 75.53 & 22.43 to 254.4 \\
\hline $65-69$ & 33.12 & 9.35 to 117.4 \\
\hline 70-74 & 22.42 & 5.75 to 87.48 \\
\hline $75-79$ & 9.83 & 1.86 to 52.03 \\
\hline \multicolumn{3}{|l|}{ Place of residence } \\
\hline Perth & 1 & \\
\hline Busselton & 1.14 & 0.83 to 1.57 \\
\hline \multicolumn{3}{|l|}{ Occupation } \\
\hline $\begin{array}{l}\text { Unemployed/retired/ } \\
\text { no occupation reported }\end{array}$ & 1 & \\
\hline Professional/managerial & 1.55 & 1.04 to 2.33 \\
\hline Skilled labour & 1.72 & 0.56 to 5.30 \\
\hline Selling/clerical & 1.08 & 0.67 to 1.73 \\
\hline Labouring/plant operation & 0.95 & 0.63 to 1.44 \\
\hline \multicolumn{3}{|l|}{ Ever use of alcohol } \\
\hline No & 1 & \\
\hline Yes & 1.76 & 1.11 to 2.78 \\
\hline \multicolumn{3}{|l|}{ Smoking status } \\
\hline Never & 1 & \\
\hline Ex-smoker & 1.56 & 1.13 to 2.14 \\
\hline $1-14$ cigarettes per day & 1.87 & 0.96 to 3.63 \\
\hline $15+$ cigarettes per day & 1.59 & 0.85 to 2.98 \\
\hline \multicolumn{3}{|l|}{ Level of total cholesterol ( $\mathrm{mmol} / \mathrm{I})$} \\
\hline$\leqslant 4.95$ & 1 & \\
\hline $4.96-5.64$ & 0.80 & 0.53 to 1.23 \\
\hline $5.65-6.41$ & 0.64 & 0.42 to 0.99 \\
\hline $6.42+$ & 0.39 & 0.24 to 0.62 \\
\hline \multicolumn{3}{|l|}{ Level of triglycerides (mmol/l) } \\
\hline$\leqslant 0.70$ & 1 & \\
\hline $0.71-1.00$ & 2.07 & 1.32 to 3.25 \\
\hline $1.01-1.50$ & 2.32 & 1.45 to 3.70 \\
\hline $1.51+$ & 2.00 & 1.20 to 3.33 \\
\hline \multicolumn{3}{|c|}{ Level of body mass index (mmol/l) } \\
\hline$\leqslant 22.58$ & 1 & \\
\hline $22.59-25.10$ & 0.78 & 0.53 to 1.15 \\
\hline $25.11-28.56$ & 0.51 & 0.34 to 0.77 \\
\hline $28.57+$ & 0.45 & 0.30 to 0.69 \\
\hline
\end{tabular}

The other biological variables tended to have a similar association with current use of HRT regardless of hysterectomy status. In both groups current use of HRT was associated with a smaller waist to hip ratio, lower body mass index, and lower levels of LDL cholesterol. HRT use was lower for women in the lowest quartile for triglycerides.

Tables 4 and 5 show the final multivariate models for use of HRT separately for women with an intact uterus and women who had undergone hysterectomy. Results of the separate analyses for biological and non-biological variables are not presented because all variables retained in these separate models remained significant when they were combined in the final models presented below. As shown in table 4, among women with an intact uterus, current use of HRT was significantly and independently associated with a higher status occupation, having ever drunk alcohol, history of past or current smoking, lower total cholesterol and higher triglycerides, and lower body mass index.

In women who had undergone hysterectomy, the only nonbiological variable retained in the final model was smoking (table 5). Current use of HRT was significantly and independently associated with lower systolic blood pressure, lower LDL cholesterol, and higher HDL cholesterol and triglycerides.

Table 6 shows the mean level of each biological variable by hysterectomy and HRT status after adjustment for age and 


\begin{tabular}{|c|c|c|}
\hline Description of variable & Odds ratio & $95 \% \mathrm{Cl}$ \\
\hline \multicolumn{3}{|l|}{ Age group } \\
\hline $35-39$ & 1 & \\
\hline $40-44$ & 0.74 & 0.23 to 2.39 \\
\hline $45-49$ & 1.33 & 0.44 to 4.01 \\
\hline $50-54$ & 2.91 & 0.99 to 8.55 \\
\hline $55-59$ & 1.87 & 0.65 to 5.41 \\
\hline $60-64$ & 1.30 & 0.43 to 3.89 \\
\hline $65-69$ & 0.86 & 0.28 to 2.65 \\
\hline $70-74$ & 0.37 & 0.11 to 1.28 \\
\hline $75-79$ & 0.52 & 0.13 to 1.99 \\
\hline \multicolumn{3}{|l|}{ Place of residence } \\
\hline Perth & 1 & \\
\hline Busselton & 1.22 & 0.82 to 1.81 \\
\hline \multicolumn{3}{|l|}{ Smoking status } \\
\hline Never & 1 & \\
\hline Ex-smoker & 1.64 & 1.10 to 2.44 \\
\hline $1-14$ cigarettes per day & 1.70 & 0.68 to 4.27 \\
\hline $15+$ cigarettes per day & 1.34 & 0.70 to 2.56 \\
\hline \multicolumn{3}{|c|}{ Level of systolic blood pressure $(\mathrm{mm} \mathrm{Hg})$} \\
\hline$\leqslant 111$ & 1 & \\
\hline $112-123$ & 0.56 & 0.31 to 1.01 \\
\hline $124-139$ & 0.59 & 0.33 to 1.06 \\
\hline $139+$ & 0.52 & 0.28 to 0.95 \\
\hline \multicolumn{3}{|c|}{ Level of $L D L$ cholesterol $(\mathrm{mmol} / \mathrm{l})$} \\
\hline$\leqslant 2.93$ & 1 & \\
\hline $2.94-3.50$ & 1.03 & 0.60 to 1.76 \\
\hline $3.51-4.20$ & 0.62 & 0.37 to 1.06 \\
\hline \multirow{2}{*}{\multicolumn{3}{|c|}{$\begin{array}{c}4.2++ \\
\text { Level of HDL cholesterol (mmol/l) }\end{array}$}} \\
\hline & & \\
\hline$\leqslant 1.25$ & 1 & \\
\hline $1.26-1.50$ & 1.65 & 0.97 to 2.80 \\
\hline $1.51-1.80$ & 2.68 & 1.56 to 4.61 \\
\hline $1.81+$ & 7.29 & 4.21 to 12.59 \\
\hline \multicolumn{3}{|l|}{ Level of trialycerides $(\mathrm{mmol} / \mathrm{l})$} \\
\hline$\leqslant 0.70$ & 1 & \\
\hline $0.71-1.00$ & 2.10 & 1.14 to 3.88 \\
\hline $1.01-1.50$ & 2.78 & 1.49 to 5.17 \\
\hline $1.51+$ & 5.00 & 2.61 to 9.57 \\
\hline
\end{tabular}

place of residence. Women who had undergone hysterectomy and were not current users of HRT had the highest mean level of systolic blood pressure, diastolic blood pressure, body mass index, waist-hip ratio, LDL cholesterol and total/HDL cholesterol ratio and the lowest mean level of HDL cholesterol of any group within the study population. The differences in means between women who had undergone hysterectomy and were not current users of HRT and the other groups of women attained statistical significance for a number of variables. Women who had undergone hysterectomy but were not using HRT clearly had a worse coronary risk factor profile than women with an intact uterus.

\section{DISCUSSION}

Using two population based cross sectional surveys this study has examined the demographic/behavioural characteristics and the biological coronary risk factor profiles of users and non-users of HRT, stratified by hysterectomy status. It should be noted that the study is limited by the lack of information about the regimen of HRT used (combined therapy or oestrogen alone) and the duration of use. It was not possible to obtain accurate information about the ovarian status of the women who had undergone hysterectomy. However, other evidence from the Western Australian Hospital Morbidity Data System for the time period under consideration, showed that the rate of bilateral oophorectomy in connection with hysterectomy was low $^{33}$ and self reports indicated that the prevalence of bilateral oophorectomy in the Perth sample was less than $10 \%$. In any case, for reasons noted earlier, hysterectomy is the important confounding variable, not ovarian status.

Because of the cross sectional nature of this investigation, it has not been possible to test formally the hypothesis that women using HRT have a lower coronary risk before beginning therapy. Nevertheless, some interesting differences according to hysterectomy status have emerged, which suggest lines for further research.

There was a strong association between hysterectomy and the use of HRT, with women who had undergone a hysterectomy much more likely to use HRT. This confirms the findings of other authors. ${ }^{15-19}$ Even so, more than half of the women in this study who had undergone hysterectomy were not using HRT.

\section{Demographic and behavioural characteristics}

The results of this study add support to previous observations in other countries that socioeconomic status and healthy behaviours may be less important as selection factors for use of HRT in women who have undergone hysterectomy than in women with an intact uterus. ${ }^{34-38}$

In this study a professional level of occupation was only significantly associated with HRT use in those with an intact uterus, which is consistent with the findings of other studies that indicators of social class, such as level of occupation and level of education are significantly associated with use of HRT

\begin{tabular}{|c|c|c|c|c|}
\hline \multirow[b]{3}{*}{ Description of biological variable } & \multirow{2}{*}{\multicolumn{2}{|c|}{$\begin{array}{l}\text { No hysterectomy } \\
\text { Current use of HRT }\end{array}$}} & \multirow{2}{*}{\multicolumn{2}{|c|}{$\begin{array}{l}\text { Hysterectomy } \\
\text { Current use of HRT }\end{array}$}} \\
\hline & & & & \\
\hline & No $n=1598$ & Yes $n=296$ & No $n=350$ & Yes $n=296$ \\
\hline $\begin{array}{l}\text { Systolic blood pressure }(\mathrm{mm} \mathrm{Hg}) \\
\text { Diastolic blood pressure }(\mathrm{mm} \mathrm{Hg})\end{array}$ & $\begin{array}{l}128.0^{*} \\
76.9\end{array}$ & $\begin{array}{l}126.6^{*} \\
76.1^{*}\end{array}$ & $\begin{array}{l}130.6 \\
77.7\end{array}$ & $\begin{array}{l}128.2^{* *} \\
77.1\end{array}$ \\
\hline Body mass index $\left(\mathrm{kg} / \mathrm{m}^{2}\right)$ & $26.0 *$ & $25.0^{*}$ & 26.9 & $25.7^{*}$ \\
\hline Waist/hip ratio & 0.79 & $0.79 *$ & 0.80 & 0.79 \\
\hline Total cholesterol $(\mathrm{mmol} / \mathrm{l})$ & 5.73 & $5.51^{*}$ & 5.73 & 5.77 \\
\hline HDL cholesterol (mmol/l) & $1.52^{*}$ & $1.54^{*}$ & 1.47 & $1.67^{*}$ \\
\hline LDL cholesterol (mmol/l) & 3.67 & $3.44^{*}$ & 3.68 & $3.46^{*}$ \\
\hline Triglycerides (mmol/l) & $1.22^{*}$ & $1.21 *$ & 1.34 & $1.45^{*}$ \\
\hline Total/HDL cholesterol ratio & $4.02 *$ & $3.83^{*}$ & 4.18 & $3.69 *$ \\
\hline
\end{tabular}

†Age adjustment included age and age squared. * $p<0.05$ for pairwise comparison with non-users of HRT who have undergone hysterectomy. ${ }^{* *} \mathrm{p}<0.10$ for pairwise comparison with non-users of HRT who have undergone hysterectomy. 
in women with an intact uterus but not in women who have undergone hysterectomy.

The association of higher social class with reduced risk of CHD is considered to be mediated through various behaviours, including diet, physical activity, and smoking habit. ${ }^{39}$ In this study, among women with an intact uterus, users of HRT were more likely to have ever drunk alcohol and to have a lower BMI but were also more likely to have a history of smoking after adjustment for other significant variables. In women who had undergone hysterectomy, the only behaviour associated with current use of HRT in the final multivariate model was having a history of smoking.

Johannes et $a l^{37}$ found, in the only prospective study stratified by hysterectomy status, that among women who had undergone hysterectomy the only single significant predictor of initiation of use of HRT was the surgery itself. On the other hand, among women with an intact uterus, regular exercise, use of alcohol and lower BMI were all significant predictors of use of HRT.

\section{Biological risk factors}

In all of the biological risk factors examined in this study, there were differences between users and non-users of HRT according to hysterectomy status. Among women who had undergone hysterectomy, current use of HRT was associated with lower levels of systolic blood pressure, LDL cholesterol, and higher levels of HDL cholesterol and triglycerides. Among women with an intact uterus, current use of HRT was associated only with lower levels of total cholesterol and higher levels of triglycerides. It has been argued that the finding of higher triglycerides is not important for coronary risk in users of HRT. In the three year PEPI randomised trial both oestrogen alone and combined HRT increased levels of triglycerides ${ }^{12}$ but the resulting higher level is not thought to be atherogenic because HRT increases triglycerides by increasing production rather than decreasing clearance. ${ }^{41} 42$ Similarly, in a French cross sectional study of women with an intact uterus, mean level of total cholesterol was found to be significantly lower in current users of combined HRT, although the mean level of triglycerides was significantly higher. ${ }^{43}$ Leaving aside the triglycerides, therefore, current use of HRT was associated, in this study, with a more favourable lipid profile, regardless of hysterectomy status, but the differences were greater among women who had undergone hysterectomy than among women with an intact uterus.

The association between current use of HRT and systolic blood pressure level was significant in the final multivariate model only in women who had undergone hysterectomy. Levels of systolic blood pressure were higher in women who had undergone hysterectomy, consistent with the findings of other studies. $^{21} 22$

In the French study cited above it was observed that levels of systolic and diastolic blood pressure were each significantly lower in users of combined HRT than in non-users. ${ }^{43}$ On the other hand, in the PEPI trial, no association was observed between use of HRT and level of blood pressure, however the smallest increase in blood pressure over three years of follow up was observed in women using oestrogen alone. ${ }^{12}$ Amigoni et al recently reported that current use of HRT was associated with a small but significant decrease in risk of increased blood pressure but there was no stratification by hysterectomy status. ${ }^{44}$

Women in this study who had undergone hysterectomy and were not using HRT had the highest mean level of systolic blood pressure, diastolic blood pressure, body mass index, waist to hip ratio and LDL cholesterol and total to HDL cholesterol ratio and the lowest level of HDL cholesterol. This confirms the findings of Wolf et al that among women who had undergone hysterectomy, levels of cholesterol and blood pressure were higher among non-users of HRT than among users.

\section{Key points}

- Hysterectomy status is an important confounding variable in the study of the relation between HRT and CHD.

- Selection factors for use of HRT and the association between use of HRT and level of coronary risk factors vary by hysterectomy status.

- Women who have undergone hysterectomy and are not using HRT have a significantly worse profile for CHD than did women with an intact uterus.

- Future investigations of the effect of HRT on risk of CHD should stratify results by hysterectomy status.

They were also higher than for women with an intact uterus, both users and non-users of HRT. ${ }^{21}$ Without use of HRT, women who have undergone hysterectomy seem to have a worse coronary risk factor profile than other women, which is consistent with other studies. ${ }^{20} 2239$ The relations between use of HRT, hysterectomy status, and blood pressure need further investigation.

In conclusion, this study has shown that selection factors for the use of HRT and the association between use of HRT and a woman's coronary risk factor profile vary by hysterectomy status. In women who have undergone hysterectomy, current use of HRT is associated with an improved profile for risk of CHD in terms of lipid metabolism and systolic blood pressure that does not seem to be associated with healthy behaviours. These results suggest that the extent of any bias in estimates of the protective effect of HRT on risk of CHD in observational studies is likely to depend on the prevalence of hysterectomy within the study population. ${ }^{365}$ It was not possible in this study to determine the relative contributions of hysterectomy status and the HRT regimen used. The results of this study underscore the importance of stratifying by hysterectomy status in future studies that investigate the effect of HRT on risk of CHD.

\section{ACKNOWLEDGEMENTS}

The authors thank the Busselton Population Medical Research Foundation for access to the survey data and the community of Busselton for their long-standing cooperation and support for the Busselton Health Study.

\section{Authors' affiliations}

L J Lambert, J A Y Straton, M W Knuiman, H C Bartholomew,

School of Population Health, University of Western Australia

Funding: we acknowledge the funding support of Healthway (WA Health Promotion Foundation) for the 1994/95 Busselton Survey, the 1994 Healthway-National Heart Foundation Risk Factor Survey and for these analyses of the data. The Public Health Research and Development Committee of the NHMRC also provided funding support for the 1994 Healthway-National Heart Foundation Risk Factor Survey through a scholarship to Dr Lambert.

Conflicts of interest: none.

\section{REFERENCES}

1 Stampfer M, Colditz G. Estrogen replacement therapy and coronary heart disease: a quantitative assessment of the epidemiologic evidence. Prev Med 1991;20:47-63

2 Grodstein F, Stampfer M, Manson J, et al. Postmenopausal estrogen and progestin use and the risk of cardiovascular disease. N Engl J Med 1996;335:453-461.

3 Grodstein F. Can selection bias explain the cardiovascular benefits of estrogen replacement therapy. Am J Epidemiol 1996;143:979-82.

4 Wilson P, Garrison R, Castelli W. Postmenopausal estrogen use, cigarette smoking, and cardiovascular morbidity in women over $50 . \mathrm{N}$ Engl J Med 1985;313:1038-43

5 Matthews KA, Kuller LH, Wing RR, et al. Prior to use of estrogen replacement therapy, are users healthier than nonusers? Am J Epidemiol 1996;143:971-8.

6 Vandenbroucke J. How much of the cardioprotective effect of postmenopausal estrogens is real? Epidemiology 1995;6:207-8. 
7 Matthews KA, Kuller LH, Wing RR, et al. Health prior to hormone use Am J Epidemiol 1996;143:983-4.

8 Posthuma W, Westendorp R, Vandenbrouche J. Cardioprotective effect of hormone replacement therapy in postmenopausal women : is the evidence biased? BM 1994;308:1268-9.

9 Herrington D, Reboussin D, Brosnihan K, et al. Effects of estrogen replacement on the progression of coronary-artery atheroscerosis. $N$ Engl J Med 2000;343:522-9.

10 Hulley S, Grady D, Bush T, et al. Randomized trial of estrogen plus progestin for secondary prevention of coronary heart disease in postmenopausal women. Heart and Estrogen/progestin Replacement Study (HERS) Research Group. JAMA 1998;280:605-13.

11 Speroff L. Postmenopausal hormone therapy and coronary heart disease:clinical implications of recent randomized trial results. Maturitas 2000;35:91-7.

12 Writing Group for the PEPI Trial. Effects of estrogen or estrogen/progestin regimens on heart disease risk factors in postmenopausal women. JAMA 1995;273:199-208.

13 Writing Group for the Women's Health Initiative Investigators. Risks and benefits of estrogen plus progestin in healthy postmenopausal women. JAMA 2002;288:321-33.

14 Fletcher SW, Colditz GA. Failure of estrogen plus progestin therapy for prevention. JAMA 2002;288:366-8

15 Brett KM, Madans JH. Use of postmenopausal hormone replacement therapy: estimates from a nationally representative cohort study. Am J Epidemiol 1997; 145:536-45.

16 Isaacs A, Britton A, McPherson K. Why do women doctors in the UK take hormone replacement therapy? J Epidemiol Community Health 1997:51:373-7.

17 Chiaffarino F, Parazzini F, Vecchia $\mathrm{CL}$, et al. Correlates of hormone replacement therapy use in Italian women, 1992-1996. Maturitas 1999;33:107-15.

18 MacLennan A. Changes in the use of hormone replacement therapy in South Australia. Med J Aust 1995;162:420-2.

19 Shelley JM, Smith AMA, Dudley E, et al. Use of hormone replacement therapy by Melbourne women. Aust J Public Health 1995; 19:387-92.

20 MacLennan AH, MacLennan A, Wilson D. The prevalence of hysterectomy in South Australia. Med J Aust 1993;158:807-9.

21 Wolf $\mathbf{P}$, Madans J, Finucane F, et al. Reduction of cardiovascular disease-related mortality among postmenopausal women who use hormones: evidence from a national cohort. Am J Obstet Gynecol $1991 ; 164: 489-94$

22 Luoto R, Kaprio J, Reunanen A, et al. Cardiovascular morbidity in relation to ovarian function after hysterectomy. Obstet Gynecol 1995:85:515-22.

23 Gordon T, Kannel W, Hjortland M, et al. Menopause and coronary heart disease. The Framingham Study. N Engl J Med 1978;313:103843.

24 Rosenberg L, Hennekens C, Rosner B, et al. Early menopause and the risk of myocardial infarction. Am J Obstet Gynecol 1981;139:47-51.

25 Jacobs HS, Loeffler FE. Postmenopausal hormone replacement therapy. BM 1992;305: 1403-8.

26 Siddle N, Sarrel P, Whitehead M. The effect of hysterectomy on the age at ovarian failure : identification of a subgroup of women with premature loss of ovarian function and literature review. Fertil Steril 1987; 47:94-100.
27 Ranney B, Abu-Ghazaleh S. The future function and forture of ovarian tissue which is retained in vivo during hysterectomy. Am J Obstet Gynecol 1977;128:626-34

28 Beavis E, Brown J, Smith M. Ovarian function after hysterectomy with conservation of the ovaries in pre-menopausal women. J Obstet Gynaecol $\mathrm{Br}$ Comm 1969;76:969-78.

29 Scientific Group of the WHO. Research on the menopause in the 1990's. Geneva: World Health Organisation, 1996.

30 Mosca L, Grundy S, Judelson D, et al. Guide to preventive cardiology for women. J Am Coll Cardiol 1999;33:1751-5.

31 Rosano GM, Graziottin A, Fini M. Cardioprotective effects of ovarian hormones and the HERS in perspective. Maturitas 2000;34:S3-10.

32 Knuiman M, Jamrozik K, Welborn T, et al. Age and secular trends in risk factors for cardiovascular disease in Busselton. Aust J Public Health 1995: 19:375-82.

33 Broadhurst R, Lambert L, Jamrozik K, et al. Hysterectomy: the major cause of premature menopause? Auckland, New Zealand: Australasian Menopause Society Annual Congress 1998.

34 Moorhead T, Hannaford P, Warskyj M. Prevalence and characteristics associated with use of hormone replacement therapy in Britain. $\mathrm{Br} J$ Obstet Gynaecol 1997;104:290-7.

35 Lancaster $T$, Surman $G$, Lawrence $M$, et al. Hormone replacement therapy: characteristics of users and non-users in a British general practice cohort identified through computerised prescribing records. J Epidemiol Community Health 1995;49:389-94.

36 Hemminki E, Malin M, Topo P. Selection to postmenopausal therapy by women's characteristics. J Clin Epidemiol 1993;46:211-19.

37 Johannes CB, Crawford SL, Posner JG, et al. Longitudinal patterns and correlates of hormone replacement therapy use in middle-aged women. Am J Epidemiol 1994;140:439-52.

38 Egeland GM, Matthews K, Kuller L, et al. Characteristics of noncontraceptive hormone users. Prev Med 1988;17:403-11

39 Matthews KA, Kelsey SF, Meilahn EN, et al. Educational attainment and behavioral and biologic risk factors for coronary heart disease in middle-aged women. Am J Epidemiol 1989;129:1132-44.

40 Darrow S, Russell M, Cooper M. Sociodemographic correlates of alcohol consumption among African-American and white women. Womens Health 1992; 18:35-51.

41 Walsh B, Sacks F. Effects of low dose oral contraceptives on very low density and low density lipoprotein metabolism. J Clin Invest 1993;91:2126-32.

42 Sacks F, Walsh B. Sex hormones and lipoprotein metabolism. Curr Opin Lipidol 1994;5:236-40.

43 Dallongeville J, Marecaux N, Isorez D, et al. Multiple coronary heart disease risk factors are associated with menopause and influenced by substitutive hormonal therapy in a cohort of French women. Atherosclerosis 1995;118:123-33.

44 Amigoni S, Morelli P, Parazzini F, et al. Determinants of elevated blood pressure in women around menopause: results from a cross-sectional study in Italy. Maturitas 1999;34:25-32.

45 Derby C, Hume AL, McPhillips J, et al. Prior and current health characteristics of postmenopausal estrogen replacement therapy users compared with nonusers. Am J Obstet Gynecol 1995;173:544-50. 